NASA Technical Memorandum 101718

\title{
An In-Flight Interaction of the X-29A Canard and Flight Control System
}

Michael W. Kehoe, Edward J. Laurie, and Lisa J. Bjarke

April 1990

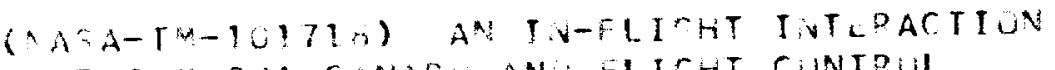

$$
\begin{aligned}
& \times 70-25+73
\end{aligned}
$$

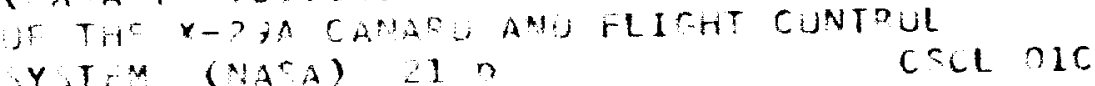

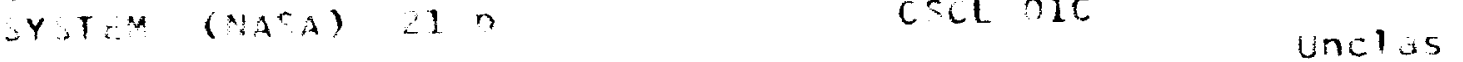

$$
\begin{aligned}
& \text { 3.3 } 05099571
\end{aligned}
$$



NASA Technical Memorandum 101718

\section{An In-Flight Interaction of the X-29A Canard and Flight Control System}

Michael W. Kehoe and Lisa J. Bjarke

Ames Research Center, Dryden Flight Research Facility, Edwards, California

Edward J. Laurie

Grumman Aerospace Corporation, Bethpage, New York

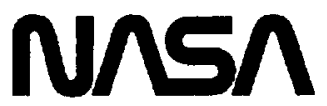

National Aeronautics and

Space Administration

Ames Research Center

Dryden Flight Research Facility

Edwards, California 93523-0273 



\section{AN IN-FLIGHT INTERACTION OF THE X-29A CANARD AND FLIGHT CONTROL SYSTEM}

\author{
Michael W. Kehoe* \\ NASA Ames Research Center \\ Dryden Flight Research Facility \\ Edwards, California
}

\author{
Edward J. Laurie** \\ Grumman Aerospace Corporation \\ Bethpage, New York
}

\author{
Lisa J. Bjarke ${ }^{\dagger}$ \\ NASA Ames Research Center \\ Dryden Flight Research Facility \\ Edwards, Califomia
}

\begin{abstract}
Many of today's high performance airplanes use high gain, digital flight control systems. These systems are liable to couple with the aircraft's structural dynamics and acrodynamics to cause an aeroservoelastic interaction. These interactions can be stable or unstable depending upon damping and phase relationships within the system. This paper presents the details of an aeroservoelastic interaction experienced in flight by the X-29A forward-swept wing airplane. A 26.5-Hz canard pitch mode response was aliased by the digital sampling rate in the canard position feedback loop of the flight control system, resulting in a $13.5-\mathrm{Hz}$ signal being commanded to the longitudinal control surfaces. The amplitude of this commanded signal increased as the wear of the canard seals increased, as the feedback path gains were increased, and as the canard aerodynamic loading decreased. The resultant control surface deflections were of sufficient amplitude to excite the structure. The flight data presented shows the effect of each component (structural dynamics, aerodynamics, and flight control system) for this acroscrvoclastic interaction.

\section{Nomenclature}

$\mathrm{A} / \mathrm{D}$ analog to digital

ASE acroservoelastic

\footnotetext{
- Structural Dynamics Group Leader, Member AIAA.

** Engineering Specialist Aeroservoelasticity, Member AIAA.

${ }^{\dagger}$ Acrospace Engineer, Member AIAA.

Copyright $(1990$ by the American Institute of Aeronautics and Astronautics, Inc. No copyright is asserted in the United States under Title 17, U.S. Code. The U.S. Government has a royalty-free license to exercise all rights under the copyright claimed herein for Governmental purposes. All other rights are reserved by the
} copyright owner.
\end{abstract}

$\begin{array}{ll}\text { CS } & \text { canard station } \\ \text { D/A } & \text { digital to analog } \\ \text { FCS } & \text { night control system } \\ g & \begin{array}{l}\text { structural damping } \\ \text { linear variable displacement } \\ \text { transducer }\end{array} \\ & \text { normal acceleration } \\ N_{z} & \text { normal automatic camber control } \\ \text { NORM ACC } & \text { normal manual camber control } \\ \text { NORM MCC } & \text { pitch rate } \\ q & \text { pitch acceleration } \\ \dot{q} & \text { sampling time } \\ T & \text { wing station } \\ \text { WS } & \text { zero order hold } \\ \text { ZOH } & \text { canard position } \\ \delta_{c} & \end{array}$

\section{Introduction}

The trend of today's aircraft design is toward more flexible structures with high gain automatic flight control systems (FCS). This trend has led to the emergence of an important design and test consideration; namely, the detection and prevention of aeroservoelastic (ASE) instabilities. An ASE instability is the adverse interaction between the aircraft's structural dynamics, aerodynamics, and FCS. This interaction is a self-excited oscillation similar to flutter. However, unlike flutter, the energy to sustain the oscillation is supplied in part by the FCS.

Analytical tools and test methods have been developed to better understand, predict, and prevent ASE 
interactions. ${ }^{1-3}$ Even so, ASE interactions may still be encountered in flight. ${ }^{4-6}$

The X-29A forward-swept wing technology demonstrator is an airplane that is statically unstable in the longitudinal axis with a flexible structure and a highgain, digital FCS. Initial flight envelope clearance testing did not reveal any ASE interactions. ${ }^{7}$ However, an increase in the canard structural response as the canard aerodynamic scals wore and an increase in the control system feedback gains for improved handling qualities led to an ASE interaction. This interaction is at a high frequency with relatively small amplitude motion and is not discemible to the pilot. This interaction was detected by monitoring the telemetered signals from the flight test instrumentation.

The ASE interaction involves the response of a high frequency structural mode that is aliased to a lower frequency as a result of the analog to digital (A/D) convertor sample rate. The aliased response is amplified by the digital FCS and then commanded to the longitudinal night control surfaces. Flight data are presented that show individually the effects of the structural dynamics, the FCS, and the aerodynamics in order to permit an assessment of each component on the overall interaction.

\section{Aircraft Description}

The X-29A aircraft (Fig. 1) incorporated many advanced technologies, the most evident being the forward-swept wing concept. The wing is made up of graphite-epoxy composite covers which are acroclastically tailored to control the structural divergence inherent in forward-swept wing designs. A thin, supercritical airfoil section is incorporated into the wing design to reduce the cruise and maneuver drag in the transonic flight regime. The wing has dual hinged, full-span flaperons at the trailing edge to provide discrete variable airfoil camber. These flaperons, in concert with the canards and strake flaps, have programmed movement to optimize the lift-to-drag ratio at any given condition in the flight envelope.

To further enhance performance, the X-29A aircraft is designed in the longitudinal axis to have approximately 35 -percent negative static stability margin subsonically and a ncutral stability margin at approximately Mach 1.4. The variable-incidence, close coupled canards located forward of the wings, the strake flaps, and the wing flaperons are used to provide longitudinal control. To employ the relaxed static stability of the aircraft safely, these three surfaces are con- trolled by a triply-redundant digital fly-by-wire FCS. As a further redundancy, each of the three computers contains an analog backup. Lateral control is provided by asymmetric deflection of the full-span wing flaperons. The single vertical fin provides the necessary directional stability and contains a conventional rudder for directional control.

The root of each canard is constructed with rubber scals which press firmly against the fuselage. These seals, shown in Fig. 2, are placed on the canard root to seal the gap between the canard and the fuselage for aerodynamic reasons. The canard is an all-moveable control surface and the primary pitch control device for the aircraft.

The FCS is designed with different operating flight control modes. The normal digital automatic camber control (NORM ACC) mode is the primary operating mode and is the mode in which the control surfaces are positioned for optimum performance. The normal digital manual camber control (NORM MCC) mode uses the same flight control gains as the NORM ACC mode. In the NORM MCC mode, the wing flaperons can be placed in a fixed position. The airplane is flown in this mode for research data acquisition only.

A complete description of the X-29A aircraft FCS is found in Ref. 8. A brief description of the longitudinal axis is given in this paper since it was in this axis that the ASE interaction occurred. The flight control laws in the longitudinal axis depend on aircraft normal acceleration, canard surface position, and pitch rate sensors for feedback signals. A simplified schematic is shown in Fig. 3. Each feedback path had notch filters and prefilters (anti-aliasing filters) incorporated. Notch filters are provided for attenuation of structural mode responses in each feedback path. The canard position feedback path has a filter to attenuate the first fuselage bending mode $(\sim 11.5 \mathrm{~Hz})$. The pitch rate feedback path has filters to attenuate the first fuselage bending mode $(\sim 11.5 \mathrm{~Hz})$, the second fuselage bending mode $(\sim 24 \mathrm{~Hz})$, and the second symmetric wing bending mode $(\sim 26 \mathrm{~Hz})$. The normal acceleration feedback path has filtcrs to attenuate the first fuselage bending mode $(\sim 11.5 \mathrm{~Hz})$, the nose boom bending mode $(\sim 21 \mathrm{~Hz})$, the canard pitch mode $(\sim 22 \mathrm{~Hz})$, and the second fuselage bending mode $(\sim 24 \mathrm{~Hz})$.

The flight control computer hardware is existing, off-the-shelf hardware from another airplane. The computer sample rate is 80 samples/sec and each prefilter break frequency is set at approximately $32 \mathrm{~Hz}$. 
This hardware is used for both the longitudinal and lateral-directional axes for the X-29A airplane. The computer processes one data sample for the longitudinal axis and the altemate sample for the lateraldirectional axis. Consequently, each axis is sampled at 40 samples/sec. However, it should be noted that the prefilter break frequency $(32 \mathrm{~Hz})$ remained unchanged mainly because of concerns with rigid body phase margins at high dynamic pressures. These phase margins could change by lowering the prefilter break frequency to $20 \mathrm{~Hz}$ and below. Furthermore, the control surface actuators would have limited capability to excite structural modes in the frequency range of 20 to $30 \mathrm{~Hz}$ because of their roll-off characteristics. The inability of the FCS to sustain an interaction with the structural modes in this frequency range provided further justification for not changing the prefilter break frequency.

Two X-29A airplanes were built. These airplanes were identical except for a spin-recovery parachute assembly which was installed on ship 2 . Near the end of the research flight testing on ship 1, it was desired to improve the pitch and roll rate performance of the airplane. This improvement was accomplished by increasing the flight control computer feedback path gains in both the longitudinal and lateraldirectional axes. These changes were only made in the NORM ACC flight control mode after the aircraft had completed approximately $173 \mathrm{hr}$ of flight testing. These new flight control laws were flown in both $\mathrm{X}$-29A airplanes.

\section{Instrumentation}

The airplane instrumentation which aided in detecting and investigating the ASE interaction consisted of accelerometers, static pressure taps, and flight control computer parameters. The locations of the accelerometers and the static pressure taps are shown in Fig. 4. The responses obtained from the canard accclerometers and static pressure taps are the data primarily used in this paper. The sample rates for the accelerometers and static pressure taps are 400 and 25 samples/sec, respectively.

A digital data bus provided access to the flight control computer commands and the fcedback path signals. The feedback signals are measured at the point after the analog signal is digitized and the command signals are measured at the point prior to signal conversion from digital to analog (D/A) (sec Fig. 3). The sample rate of the data bus is 40 samples $/ \mathrm{sec}$.

\section{Flight Conditions}

Scveral flight conditions were analyzed to show the individual effects of the structural dynamics, FCS, and the aerodynamics on the ASE interaction experienced with the X-29A airplane.

The effect of varying the feedback gains in the FCS on the ASE interaction is shown with data acquired at Mach numbers $0.40,0.50,0.60,0.70,0.80,0.85$, and 0.90 at an altitude of $15,000 \mathrm{ft}$. These flight conditions were sclected because the feedback path gains were increased the most at $15,000 \mathrm{ft}$ to improve the airplane handling qualities.

The effect of structural dynamics was observed primarily on the canard. Data was acquired at Mach 0.80 at $15,000 \mathrm{ft}$ for the airplane at $75,93,135,150,174$, and $182 \mathrm{hr}$ of flight. These data provided a good history of the canard structural response as a function of canard scal wear.

The effect of the acrodynamics was shown at Mach 0.90 at $30,000 \mathrm{ft}$, which was one of the design points for the airplane. For this study, the NORM MCC flight control mode was used. In this mode, the wing flaperons could be fixed at different angles and trimmed flight is maintained by changing the canard deflection angle. Four discrete canard angles $(8.4,5.1$, -0.4 , and $-4.0^{\circ}$ ) were obtained for straight and level flight at this flight condition. These data were acquired during one flight which eliminated the effect of the canard seal wear on the structural response of the canard. In addition, the flight control laws were unchanged during the acquisition of this data.

\section{Results}

\section{Description of the Aeroservoelastic Interaction}

After making the changes in the FCS to improve the airplane handling qualities, a $13.5-\mathrm{Hz}$ response was observed on the canard which was not noticed prior to the FCS modification. Vibration analyses, ground, and flight test data showed that there were no structural modes at this frequency. Power spectral density analyses revealed that the canard position feedback, canard command, flaperon command, and strake command time history response contained power at a frequency of $13.5 \mathrm{~Hz}$. The other longitudinal feedback paths (pitch rate and normal acceleration) and the lateral-directional axis did not contain any power at a frequency of $13.5 \mathrm{~Hz}$. Consequently, a $13.5-\mathrm{Hz}$ forced response was observed primarily on the canard, 
but also at attenuated levels on the strake flap and the wing. The amplitude of the canard command time history signal at $13.5 \mathrm{~Hz}$ was as high as $2^{\circ}$, peak-to-peak, at certain flight conditions. The canard surface actuator acted as a filter and attenuated the amplitude of the signal such that the canard motion was only $0.30^{\circ}$, peak-to-peak, at $13.5 \mathrm{~Hz}$.

It was determined from the test data analysis that the lowest canard structural mode (canard pitch) was at a frequency of $26.5 \mathrm{~Hz}$. The response of this mode was reflected to a lower frequency of $13.5 \mathrm{~Hz}$. This phenomenon is called aliasing. Aliasing occurs from sampling data that has a frequency higher than onehalf of the sampling rate. The A/D convertor sampling rate was 40 samples/sec and therefore has a Nyquist (or aliasing) frequency of $20 \mathrm{~Hz} .{ }^{9}$ Frequencies above $20 \mathrm{~Hz}$ will be reflected (aliased) back into the frequency range of 0 to $20 \mathrm{~Hz}$. The FCS was somewhat prone to aliasing because the $32-\mathrm{Hz}$ anti-aliasing filter break frequency used in the off-the-shelf flight computer hardware was not changed for the X-29A (see Aircraft Description section).

The power spectral density plot for the inboard canard accelerometer response is shown in Fig. 5. Each frequency in the range of 20 to $150 \mathrm{~Hz}$ that would alias to $13.5 \mathrm{~Hz}$ is identified on the plot. Note that there is a significant level of response at the canard pitch/bending mode $(42 \mathrm{~Hz})$, the canard cambering mode $(106 \mathrm{~Hz})$, and a higher order canard mode at $134 \mathrm{~Hz}$. These modes probably contributed very little to the $13.5-\mathrm{Hz}$ signal because the displacement level of these modes is less than the $26.5-\mathrm{Hz}$ pitch mode and because the contributions from these modes are further attenuated by the roll-off of the $32-\mathrm{Hz}$ antialiasing filter.

It should be noted that this ASE interaction is stable. Sufficient energy could not be provided by the FCS to excite the $26.5-\mathrm{Hz}$ canard pitch mode. This is caused by the attenuated output of the canard actuator and the D/A conversion process. The D/A process converts the signal from digital to analog waveforms using zero order hold (ZOH) circuits (see Fig. 3).

Figure 6 shows a power spectral density plot of the canard command signal at a flight condition of Mach 0.80 at $15,000 \mathrm{ft}$, after passing through the $\mathrm{ZOH}$. The data indicates power at frequencies of $13.5 \mathrm{~Hz}$ and $26.5 \mathrm{~Hz}$. The digital data can only have a frequency content of 0 to $20 \mathrm{~Hz}$ before it is converted to analog. This frequency bandwidth is caused by the sample rate of 40 samples/sec and corresponding Nyquist frequency of $20 \mathrm{~Hz}$. The response at $26.5 \mathrm{~Hz}$ is a reflection of $13.5 \mathrm{~Hz}$ but attenuated in amplitude. This is a characteristic of the $\mathrm{ZOH}$. In fact, all frequencies below the Nyquist frequency are reflected to frequencies above the Nyquist frequency but at attenuated amplitudes. ${ }^{10}$ These reflections are repeated in sidebands (Fig. 6) that have a bandwidth equal to sample rate.

The canard actuator response, shown in Fig. 7, revealed a large amount of attenuation at $26.5 \mathrm{~Hz}$, which is the frequency of the canard pitch mode. This attenuation, added to the attenuation from the $\mathrm{ZOH}$, would allow virtually no energy to be transferred to the structure at this frequency. The total attenuation effectively created an open loop between the canard position feedback and the canard command signals.

In addition, the canard pitch mode is moderately damped. The aliasing of the canard pitch mode response further increased the apparent damping of that mode, which made the system even more stable. This effect, shown in Fig. 8, was also verified with flight data analysis. This analysis indicated that the canard pitch modal damping was consistently less than the damping of the $13.5-\mathrm{Hz}$ forced response.

Finally, the $13.5-\mathrm{Hz}$ forced canard response caused by the aliasing did not correspond to any structural mode of the airplane. As a result, a sustained, limitedamplitude, sinusoidal response could not occur on the canard, unless there was no damping for the canard pitch mode at $26.5 \mathrm{~Hz}$.

\section{Effect of the Flight Control System on the Aeroservoelastic Interaction}

The FCS feedback gains were changed to improve the handling qualities of the airplane and are a function of Mach number and altitude. These gains were maximized at an altitude of $15,000 \mathrm{ft}$ to achieve the desired improvements in airplane handling qualities. Consequently, an envelope expansion flight test was conducted at this altitude with Mach numbers varying from 0.40 to 0.90 . The maximum gain change was at Mach 0.80 . The normalized loop gain for the canard position feedback path compared to the normalized peak amplitude of the $13.5-\mathrm{Hz}$ forced response is shown in Fig. 9. A comparison of these two curves showed that the canard feedback loop gain increased to a maximum value at Mach 0.80 which caused a corresponding increase in the forced response of the canard at a frequency of $13.5 \mathrm{~Hz}$. Note that the amplitude of 
the $13.5-\mathrm{Hz}$ forced response is slightly less than the canard loop gain values for Mach numbers between 0.40 and 0.80 and significantly less above Mach 0.80 . These differences can be attributed to the acrodynamic effects acting on the canard.

Figure 10 shows the canard command peak amplitude at $13.5 \mathrm{~Hz}$ as a function of flight hours for a flight condition of Mach 0.80 at $15,000 \mathrm{ft}$. These data indicate a slight increase in amplitude from 75 to 150 flight hours. This increased amplitude is attributed to the wear of the canard seal which allowed the structural response of the canard to increase (discussed in the effect of the structural dynamics section). The large increase in amplitude between 150 and $174 \mathrm{hr}$ is primarily caused by increased fecdback path gains to improve the pitch rate of the airplane.

A comparison of the canard command power spectral density plots, shown in Fig. 11, reveals the increase in magnitude at $13.5 \mathrm{~Hz}$ due to the feedback gain change. The feedback path gains were changed at approximately 173 flight hours. It was the magnitude of this change that caused the $13.5-\mathrm{Hz}$ forced response to become more noticeable on the canard. Also secn in the figure is an increase in power in the $1-$ to $3-\mathrm{Hz}$ frequency range for the data at 174 flight hours. The set of data acquired at 150 flight hours is with no control stick inputs while the data acquired at 174 flight hours contained pitch stick doublets. These inputs into the FCS are the cause of the increased power in this frequency range.

The flight test experience for the X-29A has shown that increases in the feedback path gains can result in large increases in unintentional FCS command signals. In this case, an unexpected $13.5-\mathrm{Hz}$ signal was commanded to the longitudinal axis control surfaces which resulted in a canard forced response of significant amplitude. Therefore, care must be exercised when increasing feedback gains and a combination of ground, llight, and analytical data should be reviewed in making these changes for an indication of unexpected results.

\section{Effect of the Structural Dynamics on the Aeroservoelastic Interaction}

Ground vibration testing of ship $1^{11}$ and ship $2^{12}$ revealcd that the frequency of the canard pitch mode and its associated shape was sensitive to the presence of the canard scals (Fig. 2). It was found during these tests that the frequency of the canard pitch mode decreased significantly when the seals were removed. In addi-
Lion, it was found that the frequency could be varied by changing the amount of input force used to excite the canard.

The amount of canard seal wear greatly affected the structural dynamics of the canard. As the canard seal wore, less force was exerted between the canard and the fuselage which consequently allowed the structural response of the canard to become larger. This increase in structural response amplitude was sensed by the canard linear variable displacement transducer (LVDT), aliased to a frequency of $13.5 \mathrm{~Hz}$ and then amplified in the FCS. The overall effect was to have more power (higher amplitude) at a frequency of $13.5 \mathrm{~Hz}$ in both the canard position feedback path and the canard command path. The first four data points in Fig. 10 indicated this gradual increase in amplitude. The increased power at $13.5 \mathrm{~Hz}$ was caused by the increased response of the canard pitch mode since no changes to the FCS were made during this phase of the program.

An cven more dramatic comparison of the effect of the canard seal wear on the canard structural response is shown in Fig. 12. The canard response is shown for Mach $0.40,0.60$, and 0.80 at $15,000 \mathrm{ft}$ for X-29A ships 1 and 2. The data for ship 1 is with worn seals (174 flight hours) while the data for ship 2 is with ncw seals ( 2 flight hours). Each airplane had identical flight control laws in the FCS. The new seals reduce the canard structural response. The tightness of the seals added damping to the canard structure which greatly reduced the response of the $26.5-\mathrm{Hz}$ canard pitch mode. As a result, the amplitude of the canard command signal at $13.5 \mathrm{~Hz}$ was virtually eliminated.

Figure 13 shows a comparison of power spectral densitics for the canard inboard accelerometer response for ships 1 and 2. These data indicated not only an attenuation of the canard structural response but also a frequency shift in the canard structural modes above $40 \mathrm{~Hz}$. It is belicved that the frequency shift is caused by the added damping to the canard structure by the new seals. The additional damping effectively reduces the canard unsteady aerodynamic force which could result in a frequency shift. A similar effect has also been observed with force variation studies during ground vibration testing. ${ }^{13}$

Structural changes have shown a measurable effect on the ASE stability of the X-29A. The structural dynamic characteristics of the canard were significantly affected by the canard aerodynamic seal wear. The increased structural response was sensed in the ca- 
nard position feedback path which in tum resulted in larger amplitude, longitudinal axis command signals as the seal wear increased. Other structural changes that could cause increased feedback path signals are control surface freeplay and fuel distribution changes. The control surface freeplay was measured regularly and kept within conservative limits. ${ }^{7}$ The airplane was ground tested with two different fuel loadings which showed there were no significant effects on fecdback path signals. However, it is essential to consider all possible sources that could change the structural dynamics of an airplane because even small changes have been shown to have a large effect on ASE interactions.

\section{Effect of Aerodynamics on the Aeroservoelastic Interaction}

The canard structural response was affected as the canard aerodynamic loading varied. Data were acquired to show this effect at a flight condition of Mach 0.90 at $30,000 \mathrm{ft}$ in the NORM MCC flight control mode. It should be noted that the flight condition was constant which resulted in constant FCS feedback gains. The effects of canard seal wear on the structural response were negligible since the data werc acquired in one flight. Therefore, the changes in the canard structural response are due solcly to the acrodynamics acting on the canard.

The peak amplitude of the 13.5-Hz forced response as a function of canard lift force coefficient is shown in Fig. 14. The lift force cocfficients were obtaincd by first integrating the chordwise static pressure distributions on the canard to obtain a normalized section lift coefficient. The section lift coefficients were then integrated across the span, yielding a canard lift cocfficient. Data was analyzed at four canard angles of attack $\left(8.4,5.1,-0.4\right.$, and $\left.-4.0^{\circ}\right)$. The results show that the structural response was the largest for a normalized lift coefficient of approximately zero and decreased as the normalized lift coefficient increased. The differcnce in the overall canard structural response at these two extremes is shown in the power spectral density plots in Fig. 15. Similar results for the wingtip structural response as a function of lift cocfficient are shown in Fig. 16.

It is interesting to note that the canard is nearly aerodynamically unloaded at a negative canard angle of attack $\left(-4 \cdot 0^{\circ}\right)$. This is caused by the canard being mounted in front of the wing. The upwash of the wing increases the angle of attack of the canard ${ }^{14}$ resulting in an unloaded condition at a negative angle of attack.

It was found that the structural response of the canard and the wing increased as the normalized lift coefficient decreased for each surface. The canard was of primary concem because the motion of this surface resulted in higher amplitude feedback path signals to the FCS. This data suggests that ASE flight testing should be accomplished at an angle of attack where the surface of concern is at or near zero lift.

\section{Concluding Remarks}

Aeroservoclasticity is the interaction of the aircraft's structural dynamics, aerodynamics, and flight control system. The X-29A aircraft experienced an aeroservoelastic interaction which consisted of the canard pitch mode at $26.5 \mathrm{~Hz}$ being sampled and then aliased by the flight control system to $13.5 \mathrm{~Hz}$. Flight test results indicated that each component of an aeroservoelastic interaction (structural dynamics, flight control system, and aerodynamics) could significantly contributc to the interaction.

It was found that the canard structural dynamics were affected by the amount of wear on the canard acrodynamic seals fitted between the canard root and the fuselage. As the amount of wear increased so did the structural response amplitude of the canard.

The flight control system anti-aliasing filters had a break frequency of $32 \mathrm{~Hz}$. The Nyquist frequency of the digital flight control system was $20 \mathrm{~Hz}$. The aliasing of the canard pitch mode at a frequency of $26.5 \mathrm{~Hz}$ was primarily a result of the break frequency being set above $20 \mathrm{~Hz}$.

The canard command signal increased in amplitude as a result of increased structural dynamic response of the canard and increased feedback path gains. The canard structural response was a function of canard aerodynamics and increased as the canard normalized lift coefficient decreased.

The flight experience of the X-29A has shown that aircraft with flexible structures and high gain digital flight control systems are sensitive to even small changes in the structural dynamics, aerodynamics, and flight control system feedback path gain. The effect of these changes should be analyzed, and tested on the ground and in flight to determine the extent of their effect whenever possible. 


\section{References}

${ }^{1}$ Peloubet, R.P., Jr., Haller, R.L., Cunningham, A.M., Cwach, E.E., and Watts, D., Application of Three Aeroservoelastic Stability Analysis Techniques, AFFDL-TR-76-89, Air Force Flight Dynamics Laboratory, Wright-Patterson Air Force Basc, $\mathrm{OH}$, Sept. 1976.

${ }^{2}$ Gupta, K.K., Brenner, M.J., and Voelker, L.S., "Intcgrated Aeroservoelastic Analysis Capability with X-29A Comparisons," J. of Aircraft, Volume 26, Number 1, Jan. 1989, pp. 84-90.

${ }^{3}$ Zislin, A., Laurie, E., Wilkinson, K., and Goldstein, R., "X-29 Acroservoclastic Analysis and Ground Test Validation Procedures," AlAA-85-3091, AIAA/AHS/ASEE Aircraft Design Systems and Operations Mecting, Colorado Springs, CO, Oct. 1985.

${ }^{4}$ Peloubet, R.P., Jr., "YF-16 Active-ControlSystem/Structural Dynamics Interaction Instability," AIAA-75-823, AIAA/ASME/SAE 16th Structures, Structural Dynamics, and Materials Conference, Denver, CO, May 1975.

${ }^{5}$ Kchoe, M.W., Highly Maneuverable Aircraft Technology (HiMAT) Flight-Flutter Test Program, NASA TM-84907, 1984.

${ }^{6}$ Kehoc, M.W., AFTI/F-16 Aeroservoelastic and Flutter Flight Test Program-Phase I, NASA TM-86027, 1985.

${ }^{7}$ Kchoc, M.W., and Rivcra, J.A., Flutter and Aeroservoelastic Clearance of the X-29A ForwardSwept Wing Airplane, NASA TM-100447, 1989.
${ }^{8}$ Whitaker, A., and Chin, J., "X-29 Digital Flight Control System Design," AGARD-CP-384, Oct. 1984.

Y Otncs, R.K., and Enochson, L., Digital Time Series Analysis, John Wiley and Sons, Inc., New York, 1972.

${ }^{10}$ Phillips, C.L., and Nagle, H.T., Jr., Digital Control System Analysis and Design, Prentice-Hall, Inc., Englcwood Cliffs, NJ, 1984.

"Flynn, J., Martone, E., and Anderson, P., Results of the Ground Vibration Survey (GVS)/ Integrated Flight Control System (FCS) Tests of the X-29 Aircraft, GASD Report 712/ENG-RPT-85-006, Grumman Acrospace Corporation, Bethpage, NY, July 1985.

${ }^{12}$ Flynn, J., and Dilca, J., Results of the Ground Vibration Survey of the X-29A No. 2 Aircraft with Spin Chute Installation, GASD Report X29-380-TR8802, Grumman Aerospace Corporation, Bethpage, NY, Oct. 1988.

${ }^{13}$ Kehoe, M.W., F-15A/B Nestable Fuel Tank Ground Vibration, Flight Flutter, and Loads Demonstration Test Program, Air Force Flight Test Center, Edwards Air Force Base, CA, AFFTC-TR-79-14, May 1979.

${ }^{14}$ Shanker, V., and Malmuth, N., "Computational Treatment of Transonic Canard-Wing Interactions," AIAA-82-0161, AIAA 20th Aerospace Sciences Mecting, Orlando, FL, Jan. 1982. 


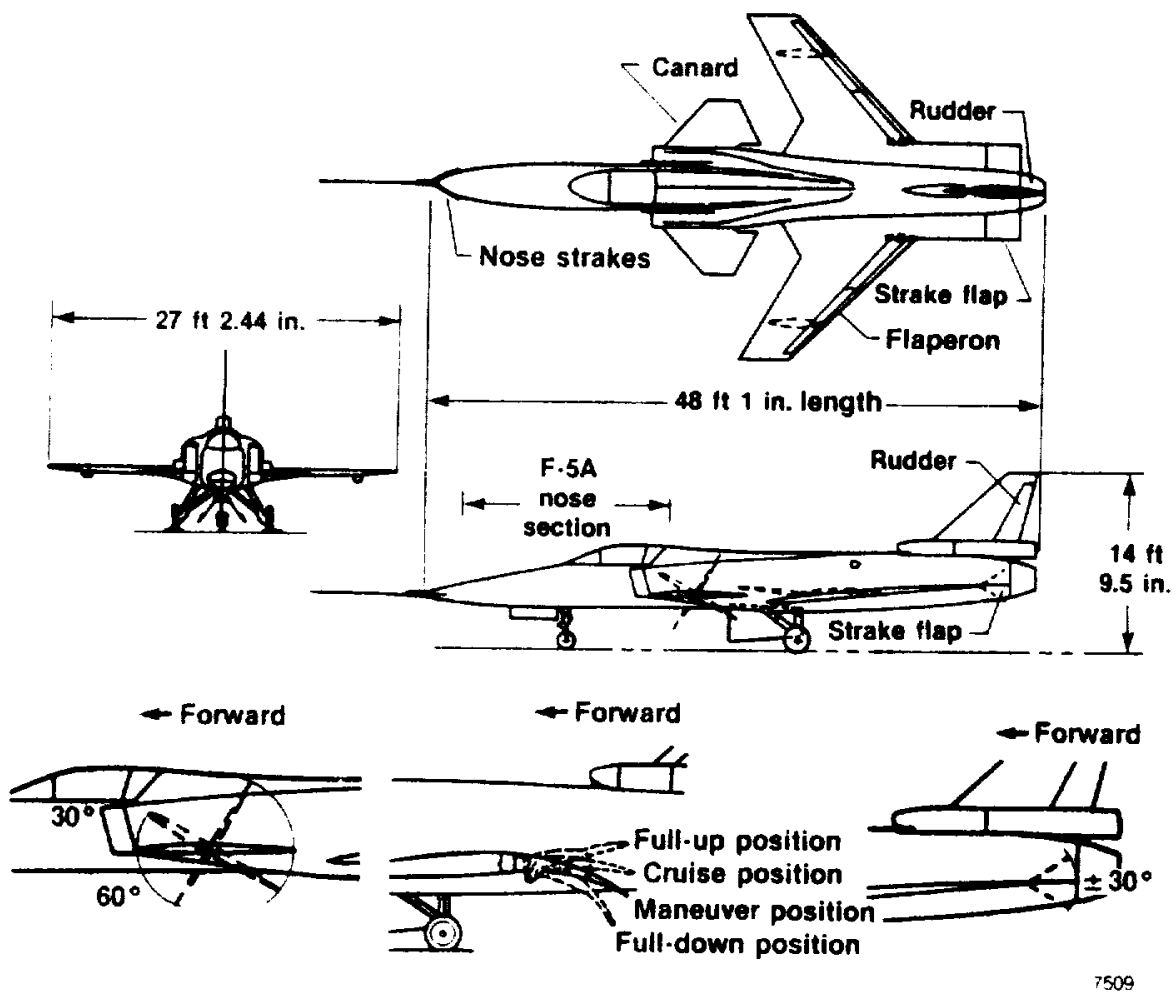

Fig. I Three view drawing of the X-29A airplane. 


\section{ORIGINAL PAGE \\ BLACK ANO WHITE PHOTOGRAPH}

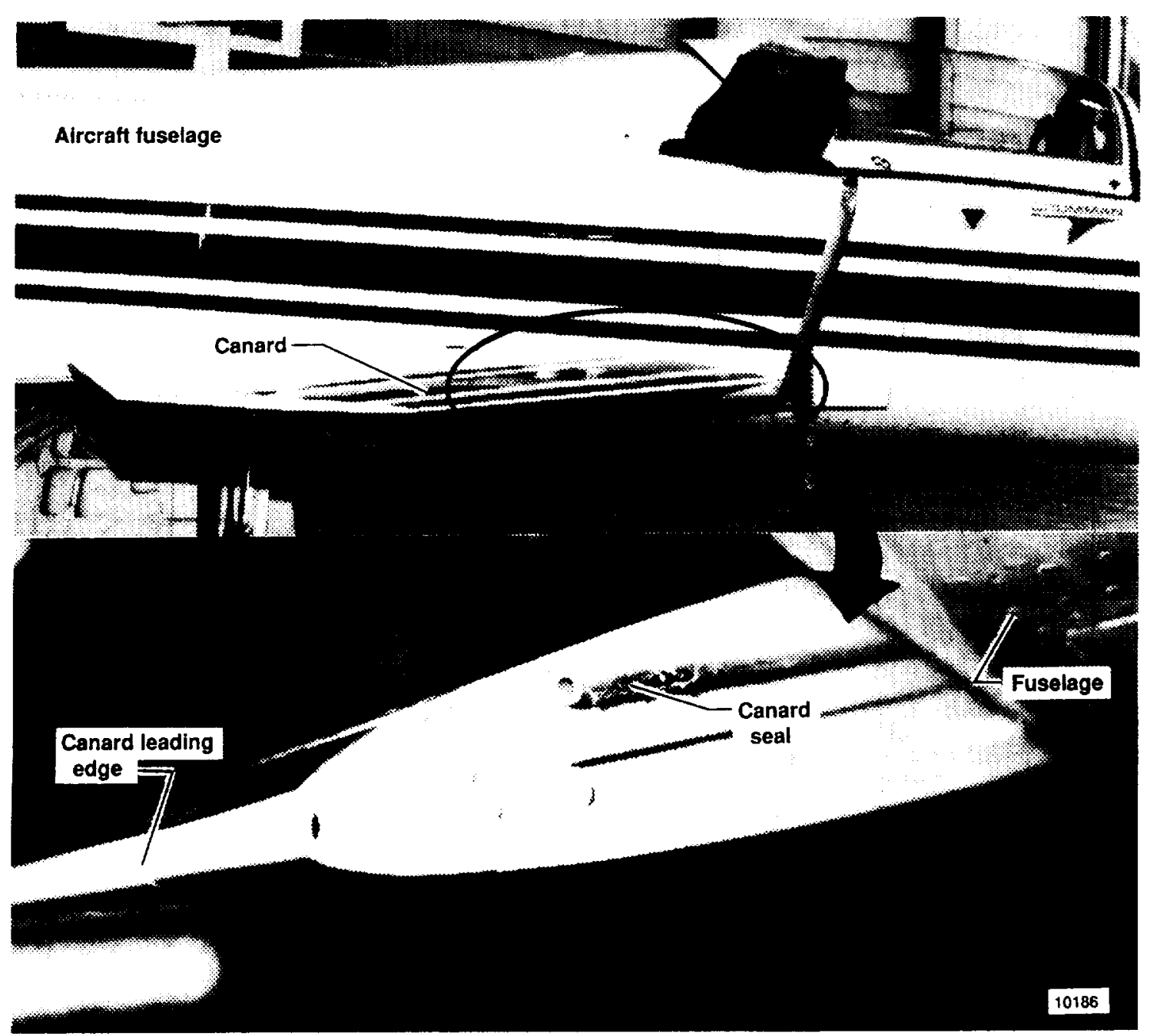

Fig. 2 X-29A airplane canard seal. 


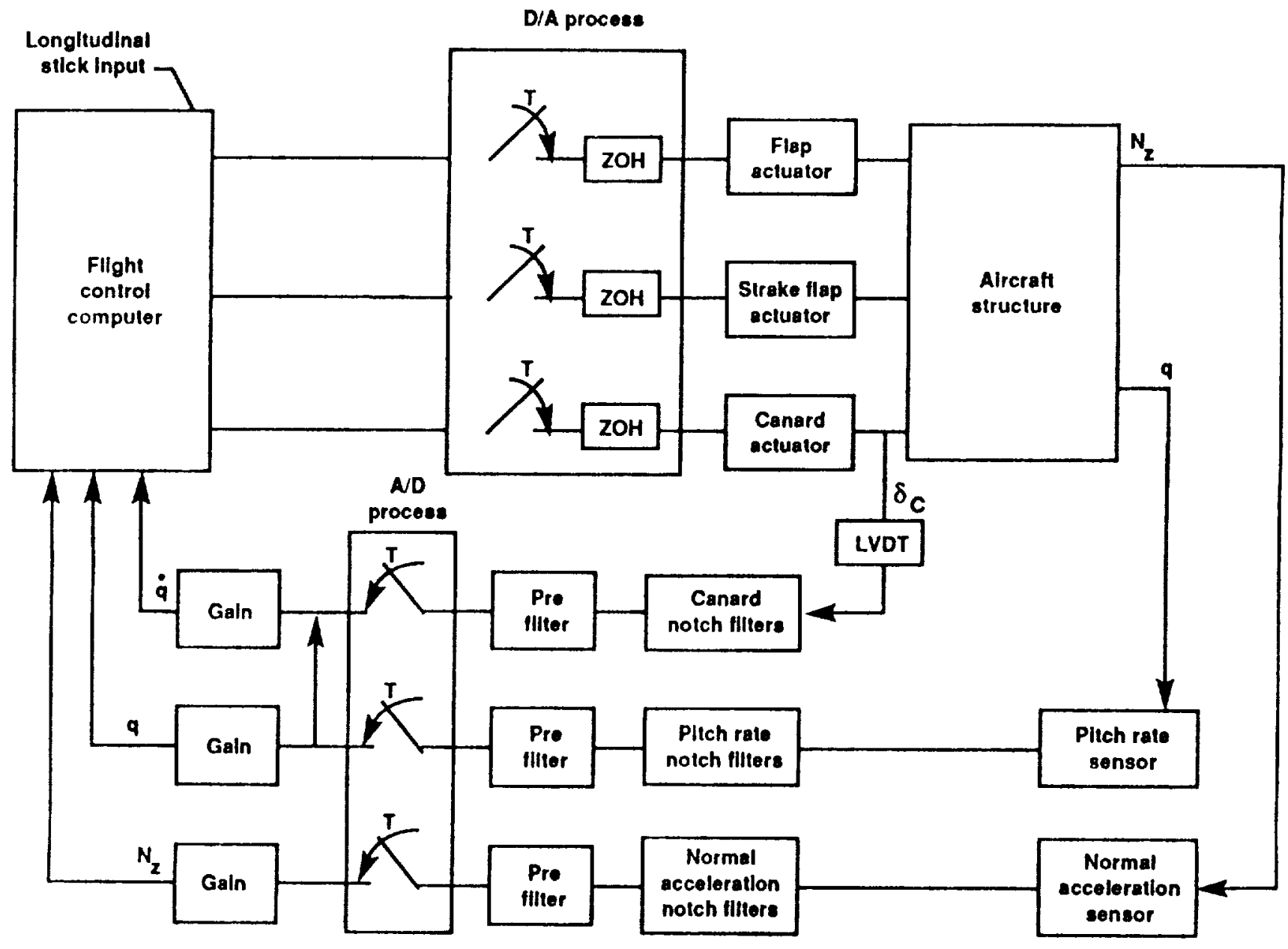

Fig. 3 Simplified longitudinal normal digital mode. 

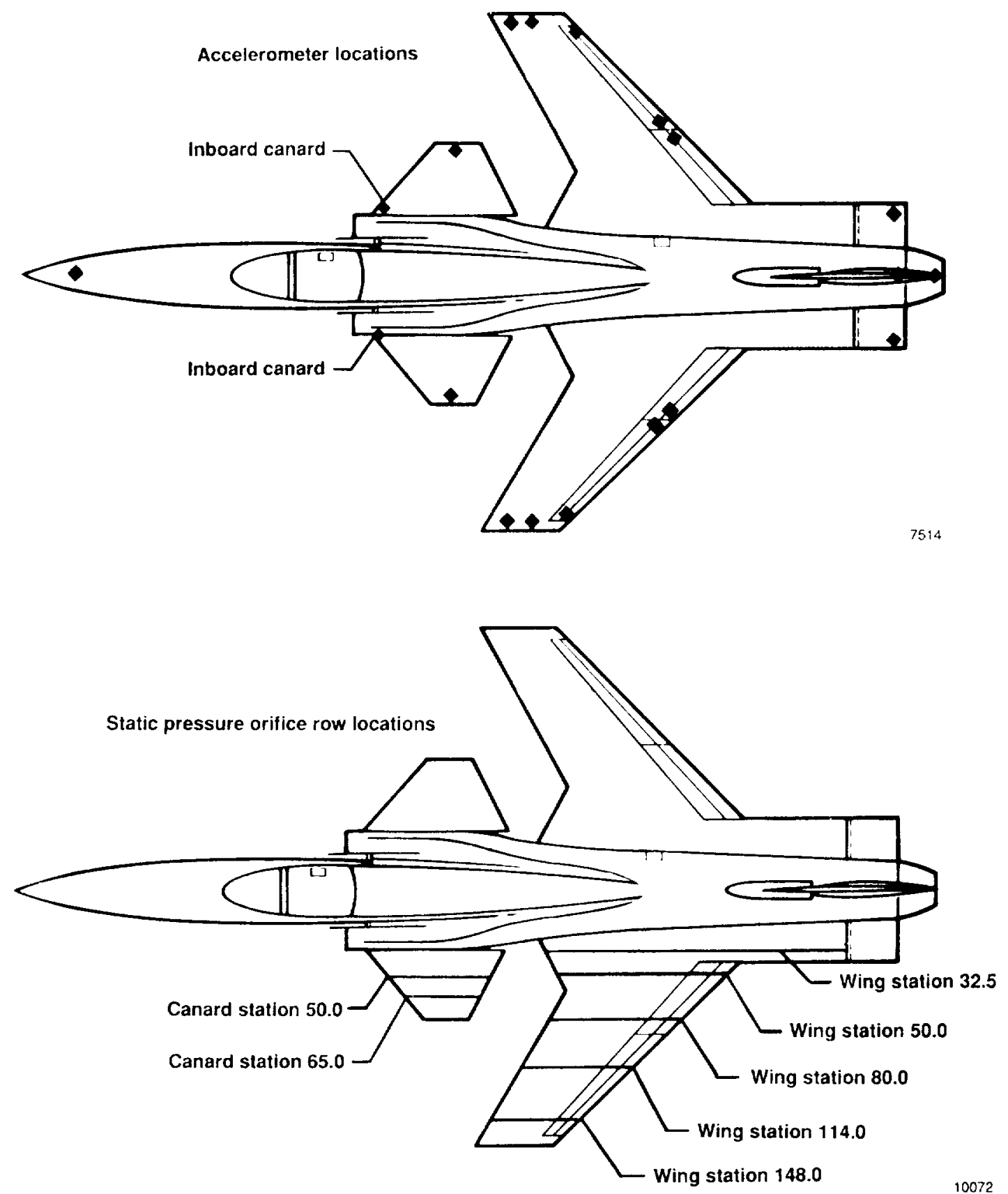

Fig. 4 Accelerometer and static pressure orifice row locations. 


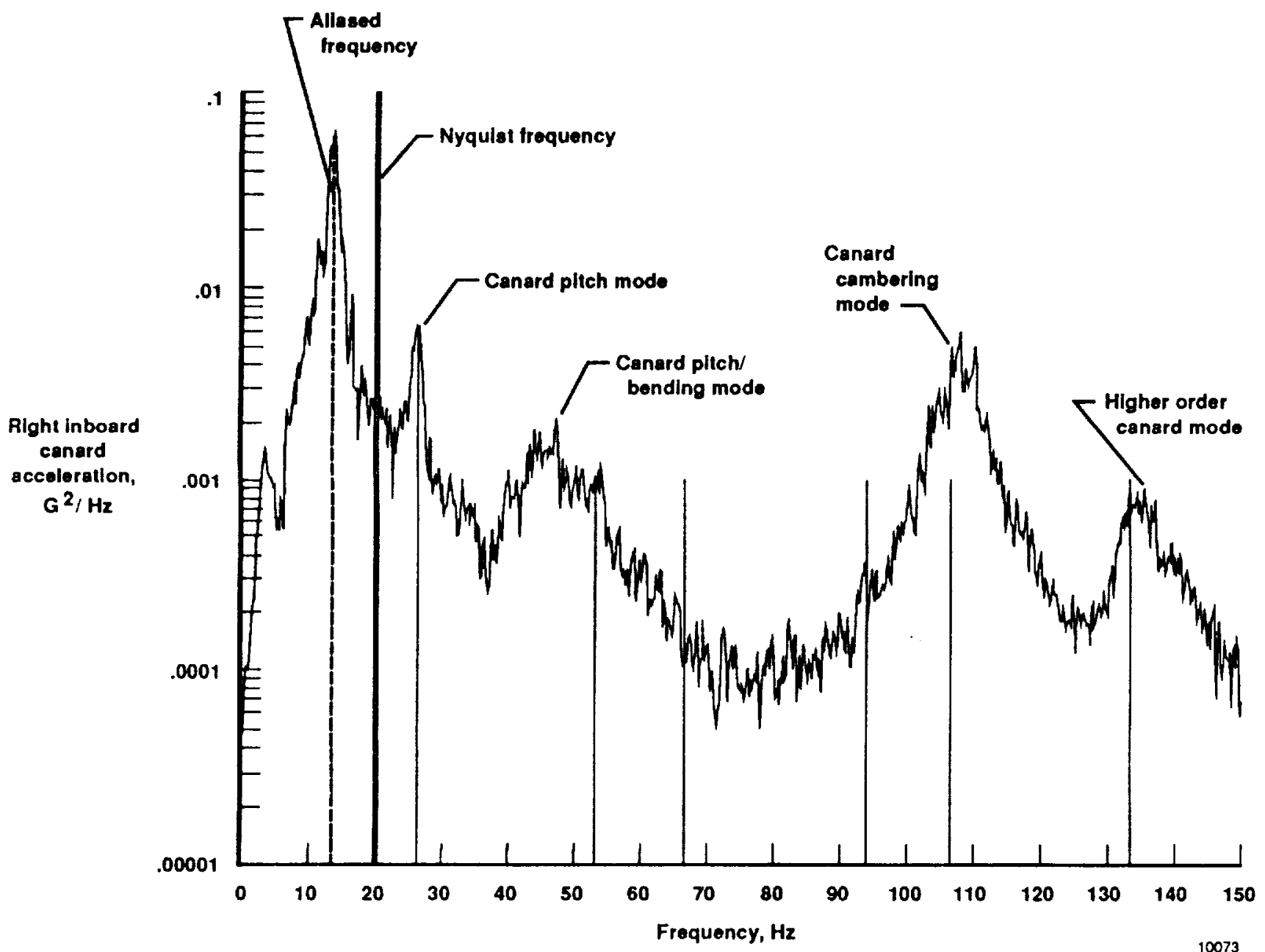

Fig. 5 Possible aliased frequencies for a 40 samples/sec sample rate. 


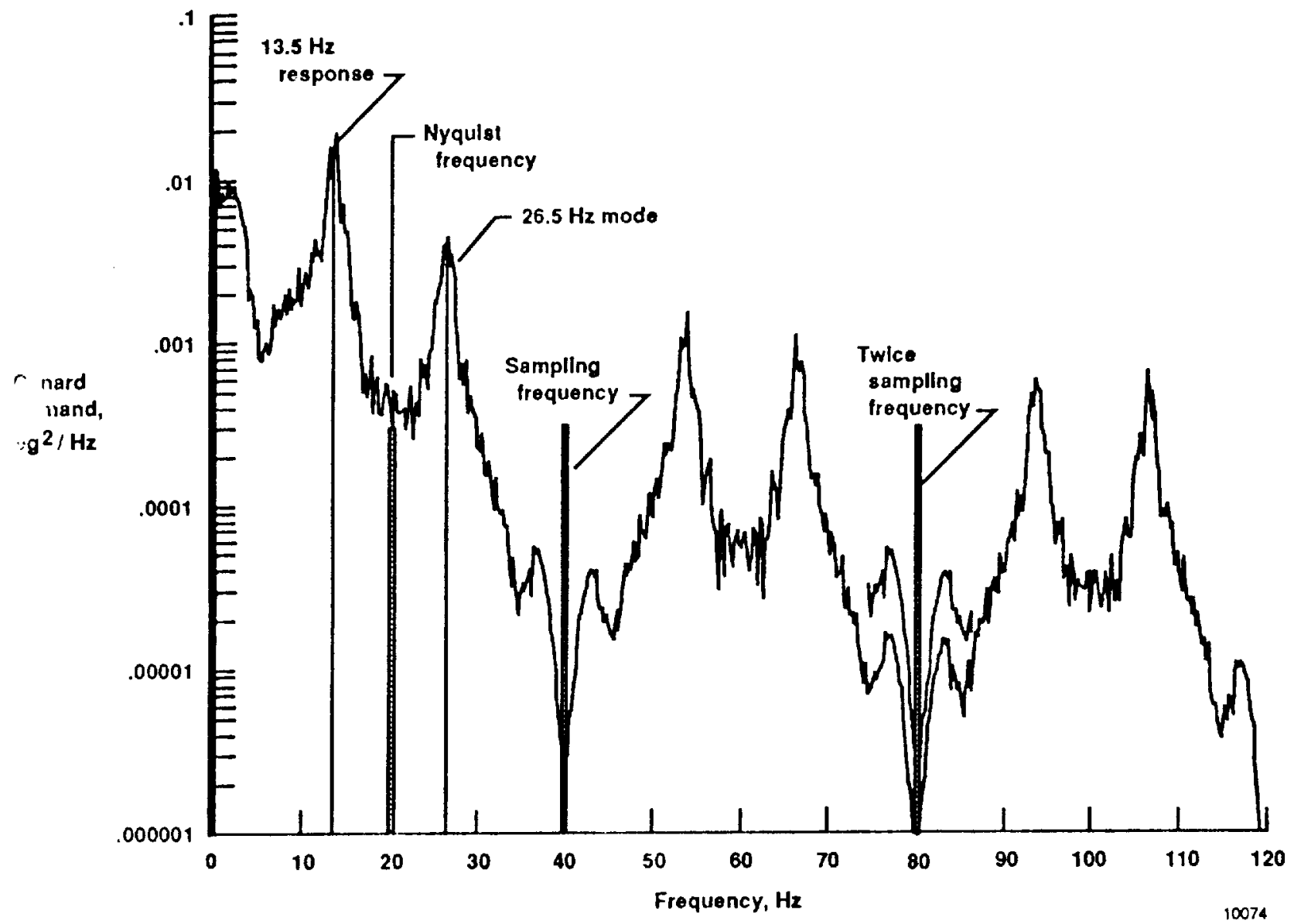

Fig. 6 Canard command zero order hold oulput signal power spectral density plot. 


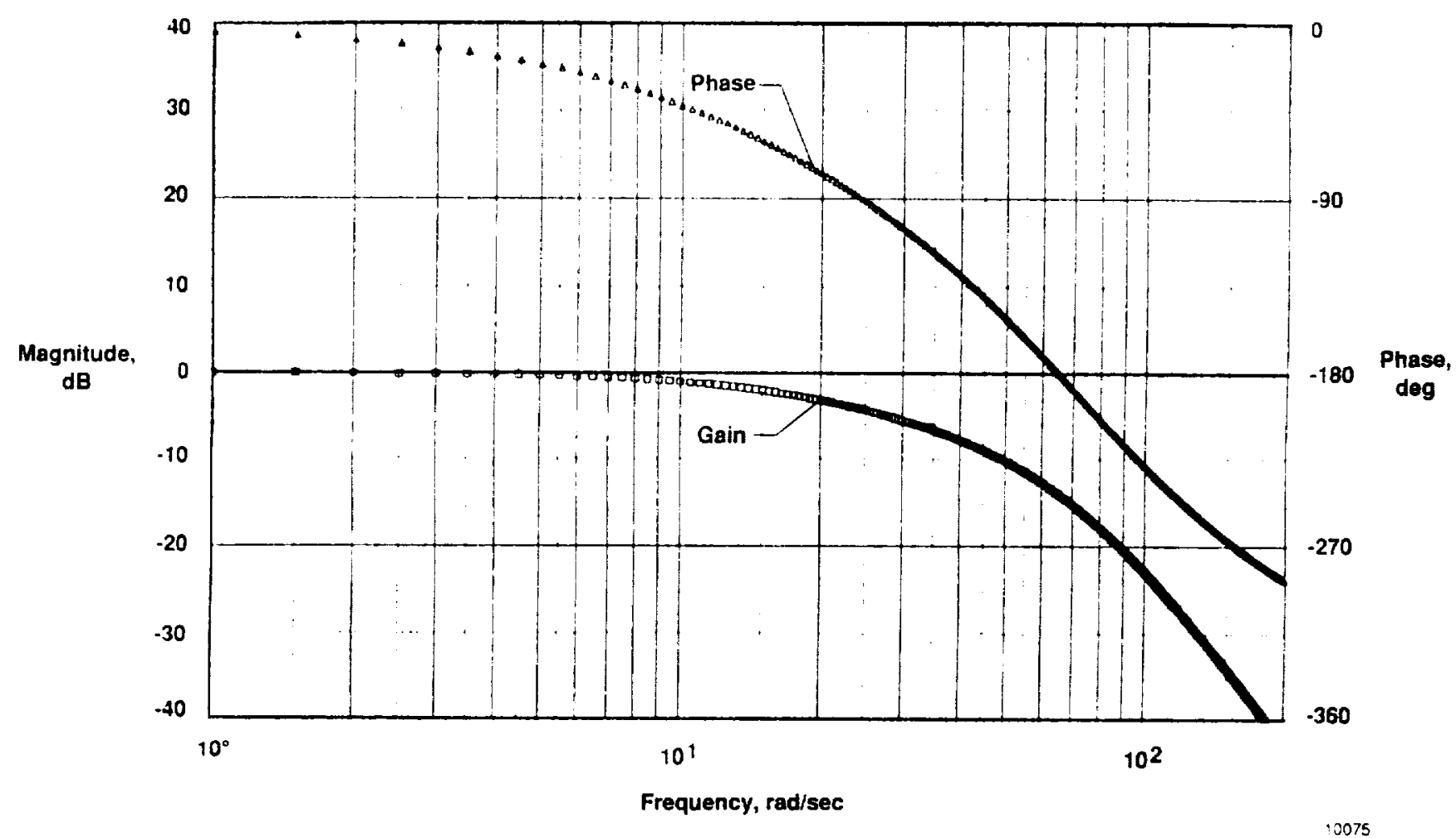

Fig. 7 Canard actuator frequency response plot.

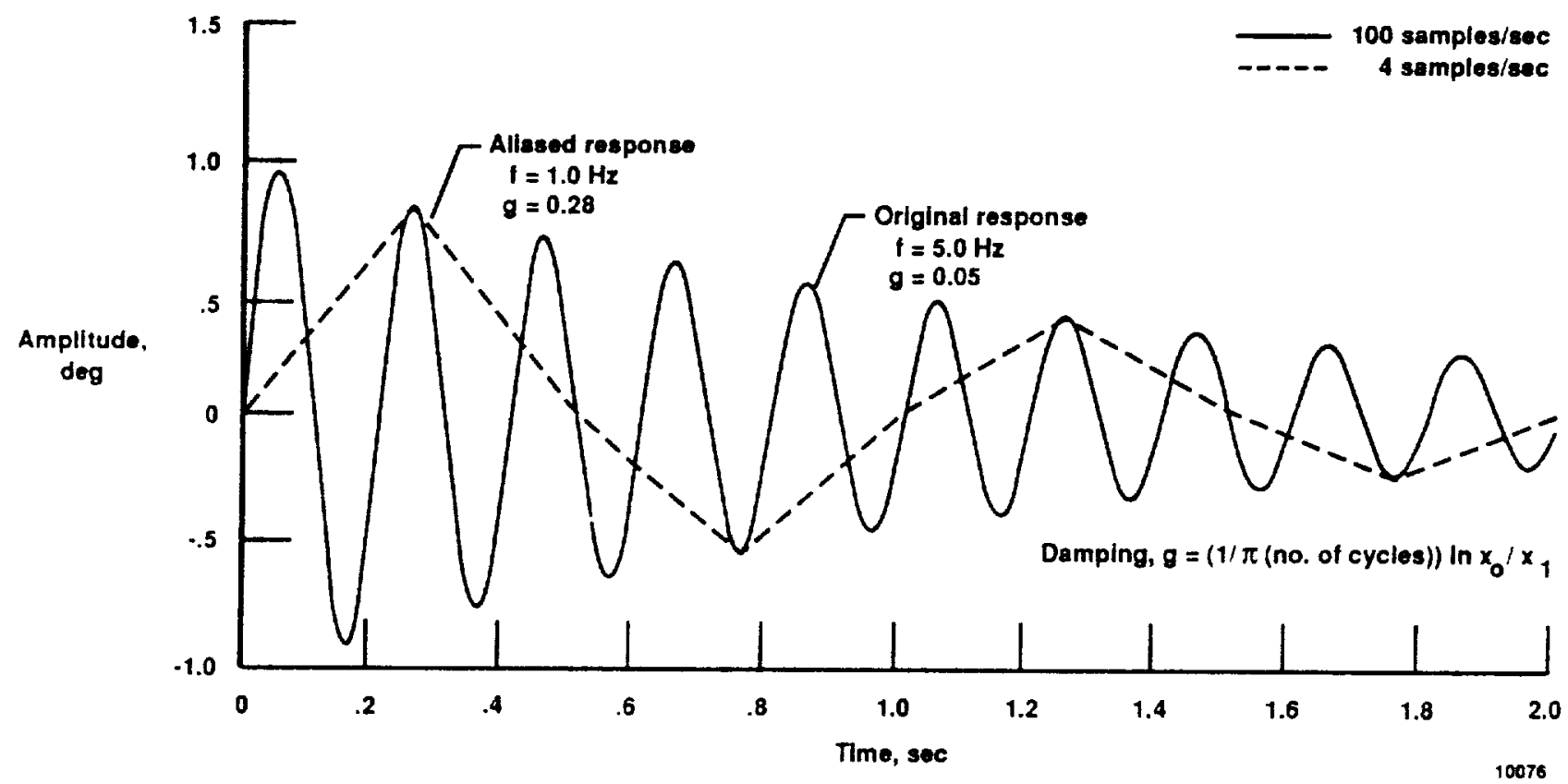

Fig. 8 Comparison of a $5-\mathrm{Hz}$ sine wave with 5-percent damping sampled at two different rates. 


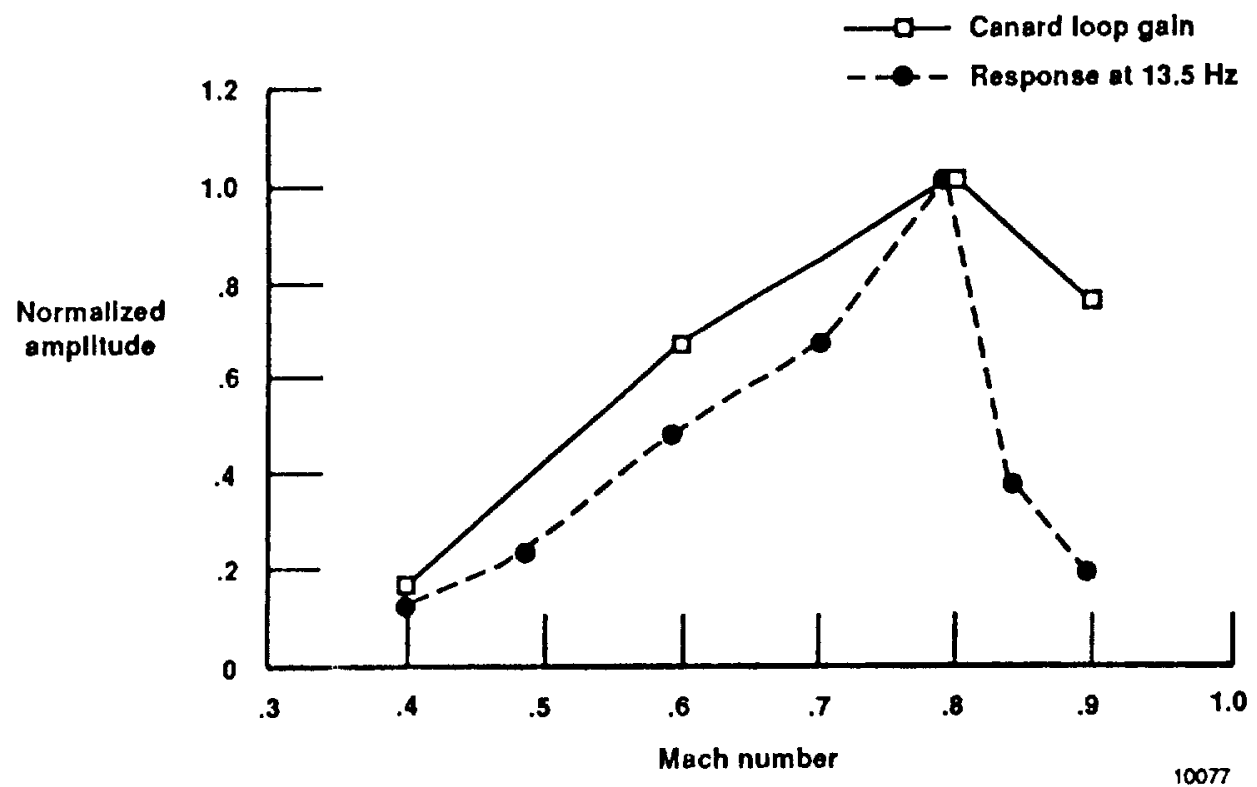

Fig. 9 Canard loop gain and forced vibration response at 15,000 ft.

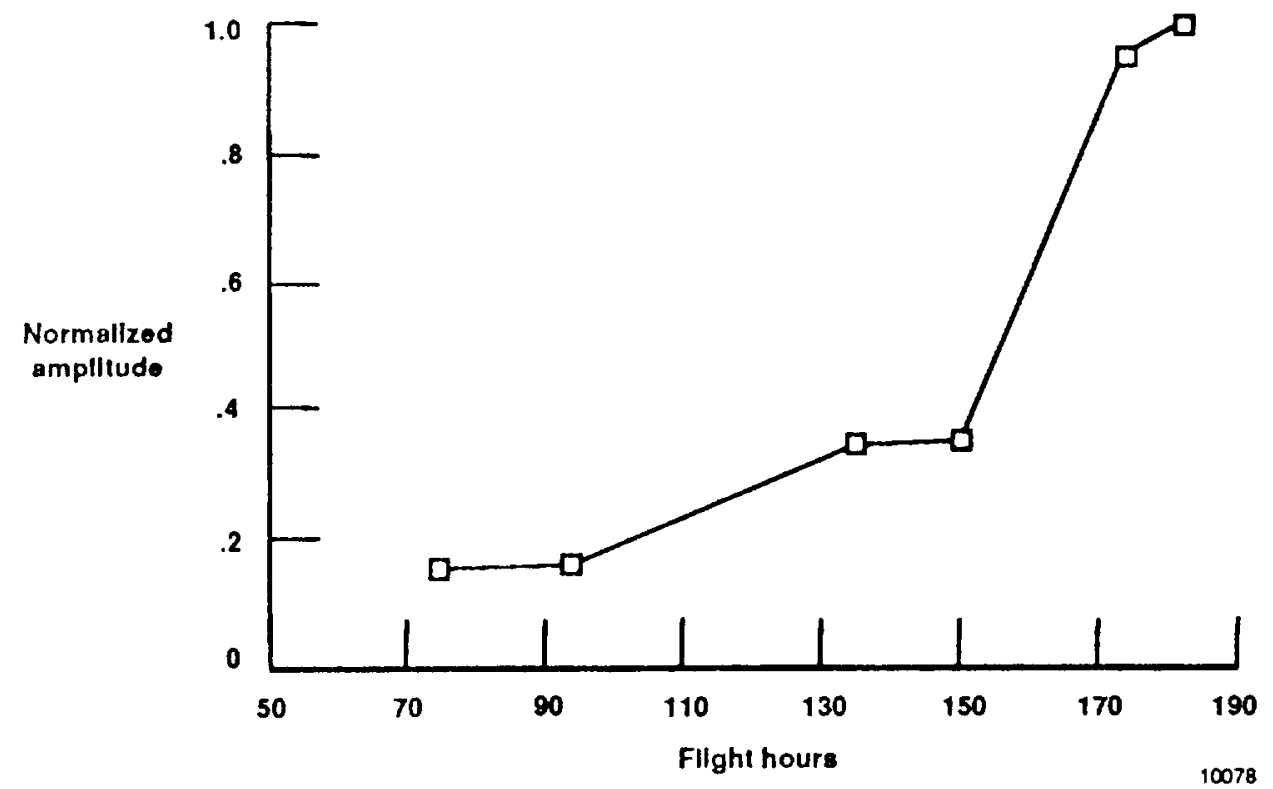

Fig. 10 Normalized peak amplitude of the canard command signal at Mach 0.80, $15,000 \mathrm{ft}$ altitude. 


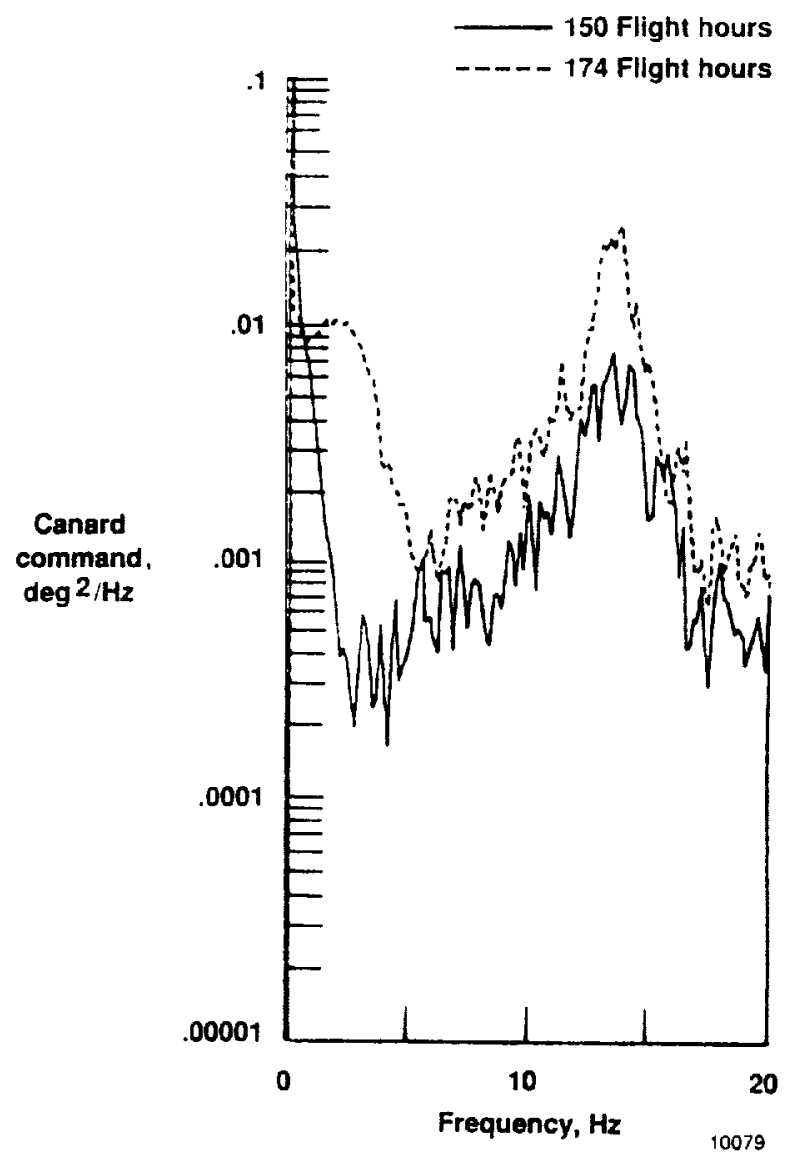

Fig. 11 Comparison of canard command power spectral density at Mach $0.80,15,000 \mathrm{ft}$ altitude.

$\longrightarrow$ Ship 1 (174 flight hours)

- - Ship 2 (2 flight hours)

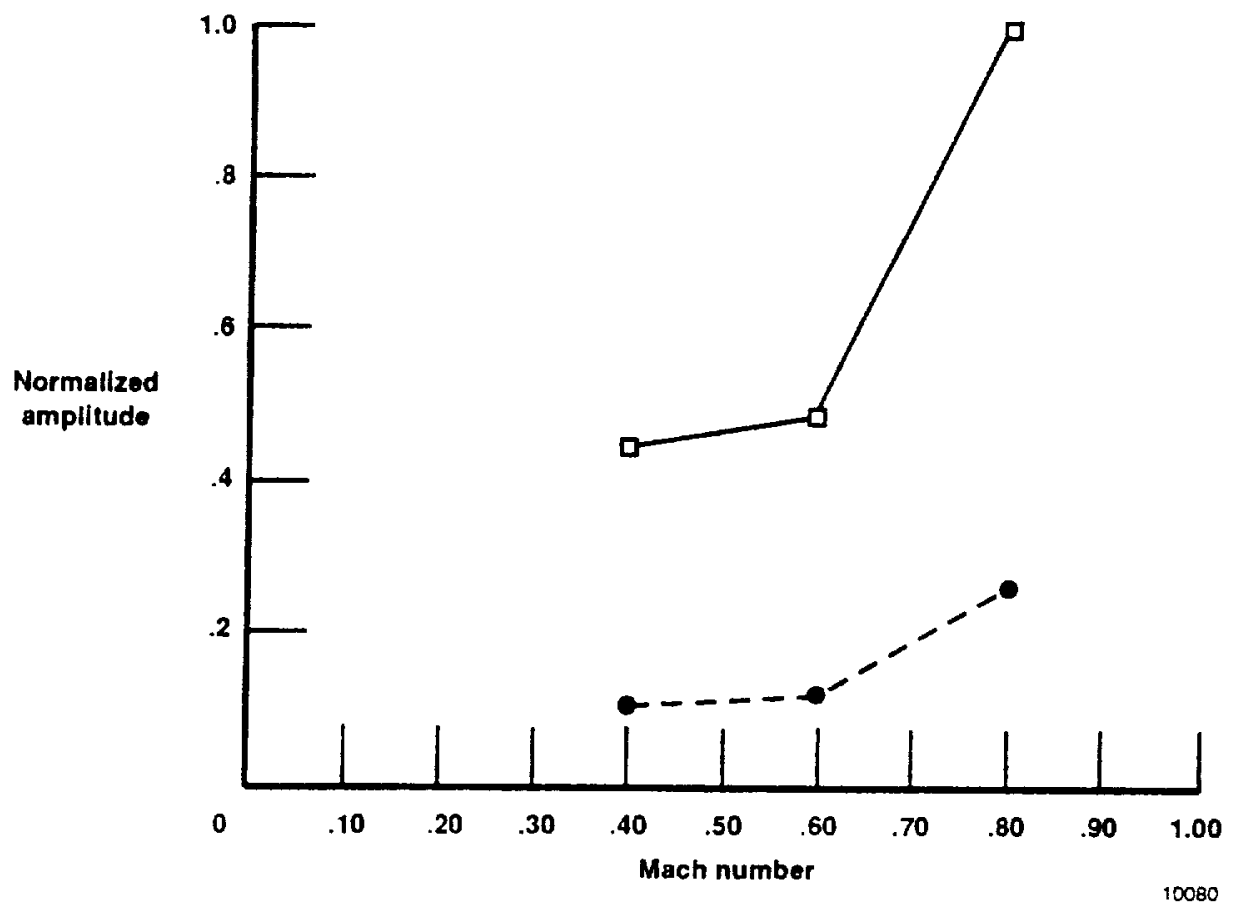

Fig. 12 Comparison of ship 1 and ship 2 canard structural response at 15,000 ft altitude. 


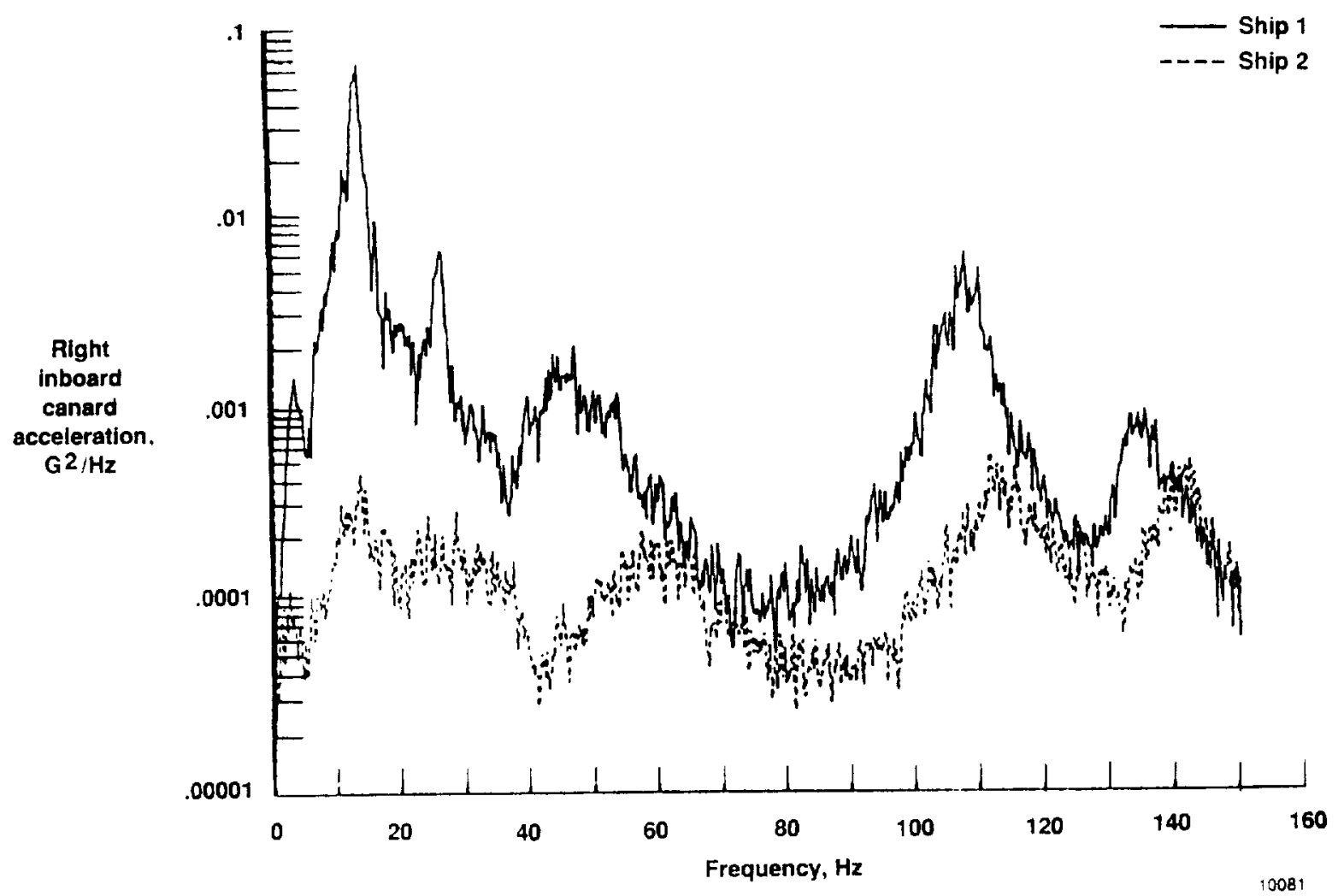

Fig. 13 Right inboard canard acceleration power spectral density plot at Mach $0.80,15,000 \mathrm{ft}$ altitude.

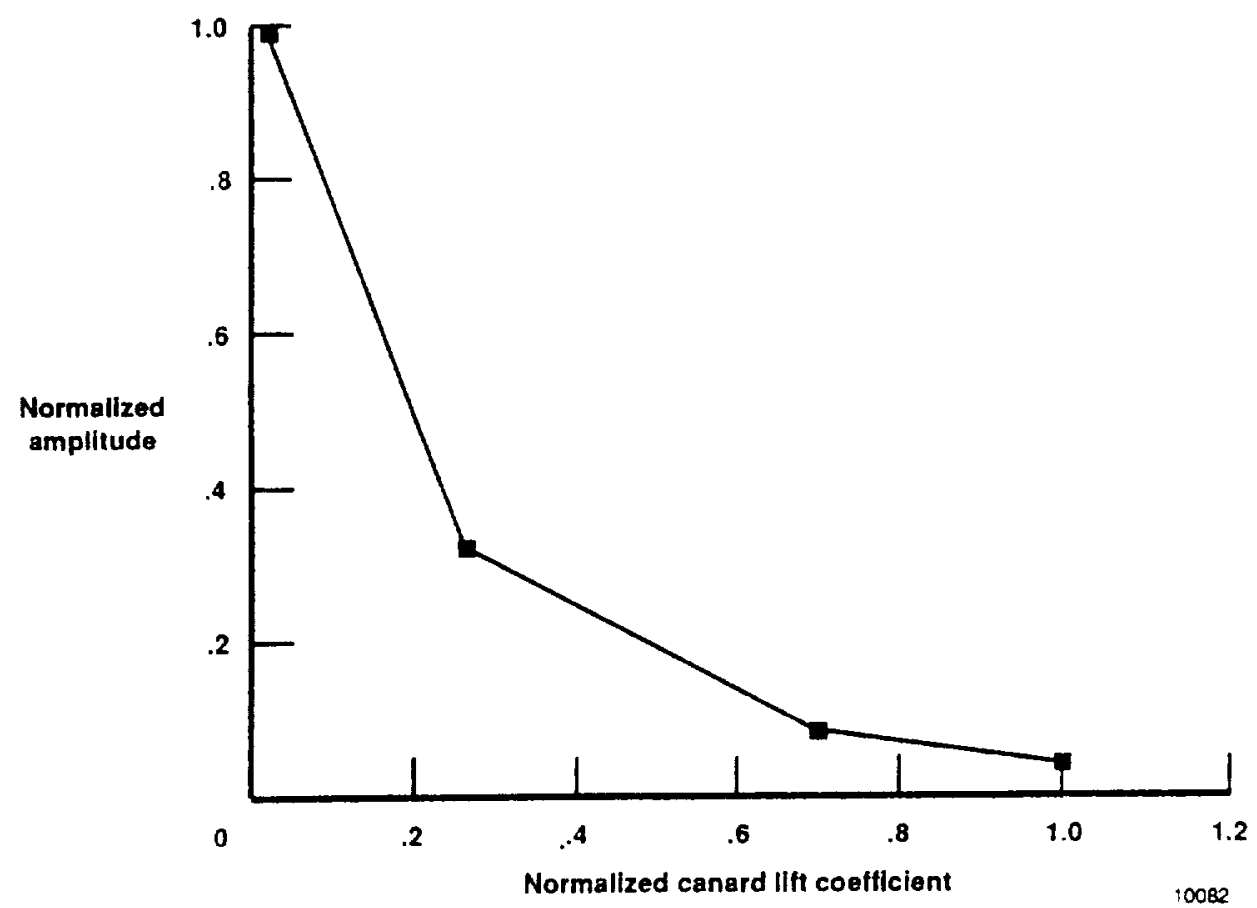

Fig. 14 Peak amplitude of the forced $13.5-\mathrm{Hz}$ response as a function of canard lift coefficient at Mach 0.90, 30,000 ft altitude. 


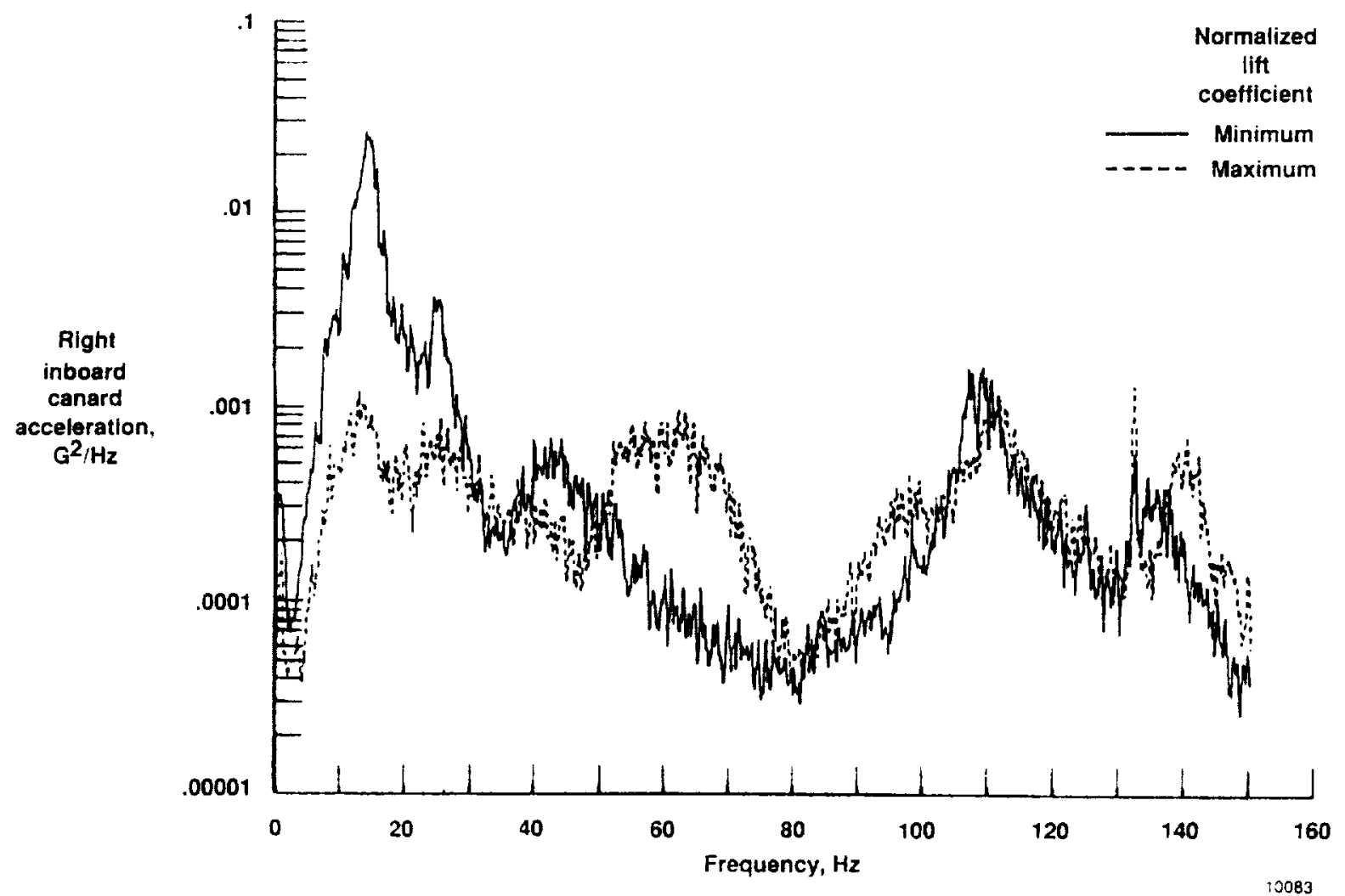

Fig. 15 Right inboard canard acceleration power spectral density plot comparison at Mach 0.90 , $30,000 \mathrm{ft}$ altitude.

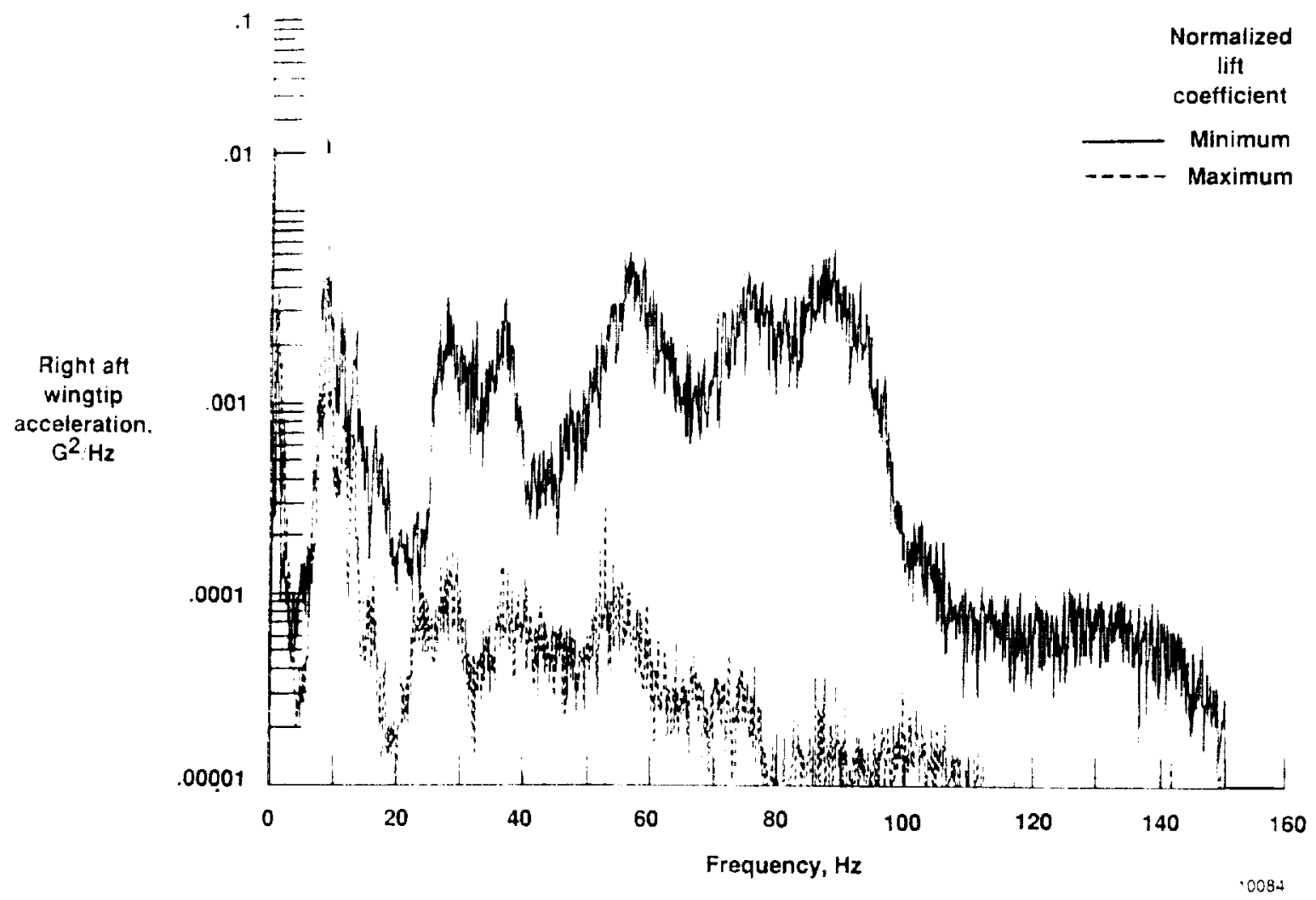

Fig. 16 Right aft wingtip acceleration power spectral density plot comparison at Mach 0.90 . $30,000 \mathrm{ft}$ altitude. 


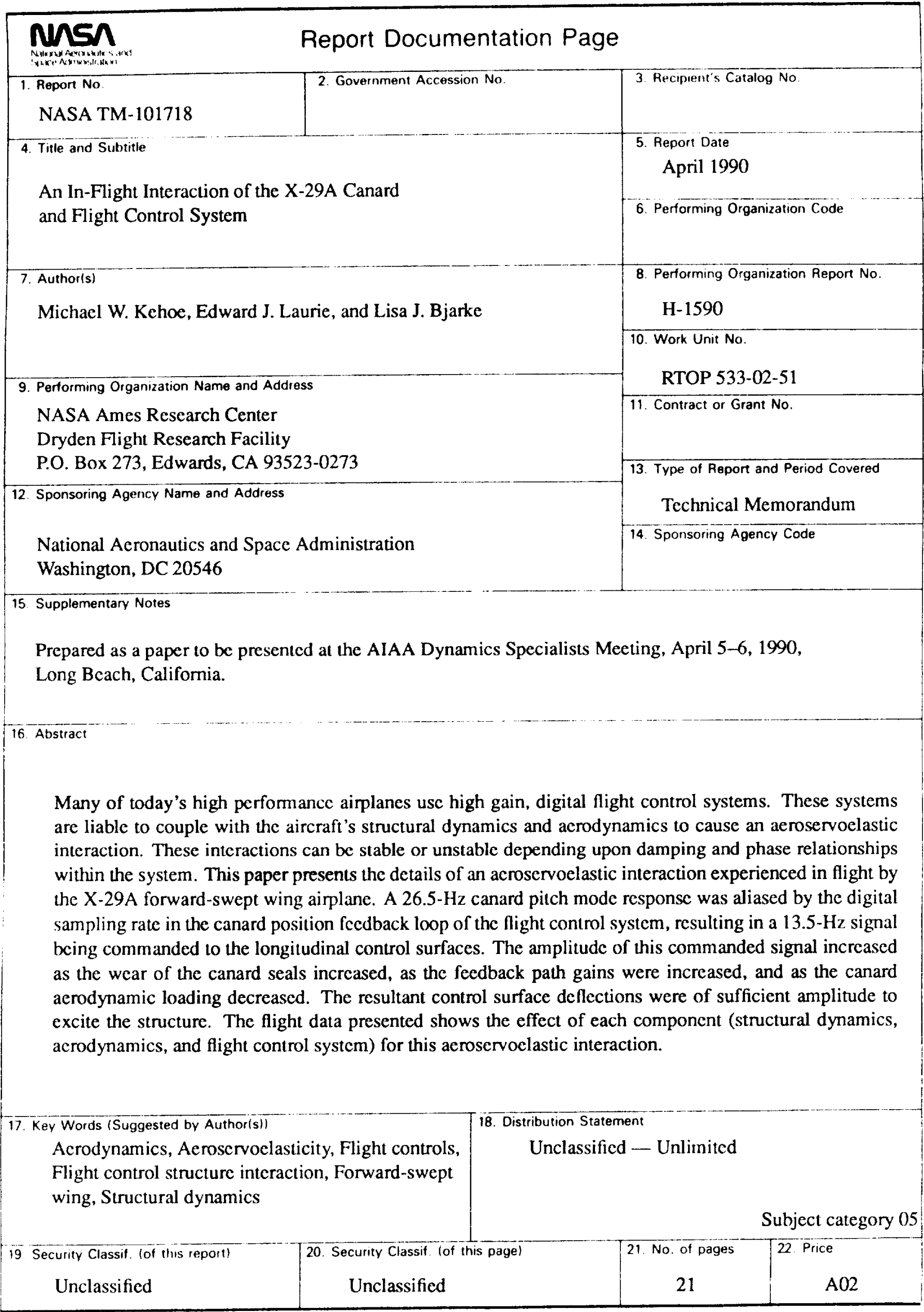


